\title{
A instituição de saúde mental como dispositivo social de produção de subjetividade
}

\author{
The mental health institution as a social \\ device for producing subjectivity
}

Abílio da COSTA-ROSA

\begin{abstract}
Resumo
Analisa-se a instituição de saúde mental como dispositivo de produção de subjetividade. Embora se trate de um setor singular da produção, a aplicação do referencial de análise das formações sociais e da mercadoria, criado por Marx, pode trazer à luz aspectos de extrema utilidade na análise da composição e dos efeitos produtivos das práticas no campo da saúde mental em nosso contexto na atualidade. Dois modos de produção destacam-se em flagrante contradição: suas lógicas são congruentes com a do modo capitalista de produção ou com a lógica dos modos de produção cooperados que o antecederam; a concepção de saúde variará radicalmente em cada caso. Conclui-se que, no âmbito da saúde psíquica e mental, a produção de saúde é indissociável da produção de subjetividade, podendo estas ser sintônicas ou dessintônicas entre si, dependendo do modo de produção em que são realizadas. Propõe-se nova definição de saúde para a atenção psicossocial.
\end{abstract}

Unitermos: Apoio social. Psicoterapia. Reforma dos serviços da saúde.

\begin{abstract}
The institution of Mental Health is analyzed as a device for producing subjectivity. Though it deals with a unique production sector, the application of the analytical frame of reference of Social Formations and the market, as espoused by Marx, may bring to light some extremely useful aspects in the analysis of the composition and productive effects of such practices in the field of mental health, within our context, at this present moment in time. Two production modes stand out in clear contradiction: their arguments are consistent with either that of the capitalist mode of production or with the cooperative mode of production that preceded it; the definition of health will vary radically according to the case. It may be concluded that, within both the psychic and mental spheres, health production is inseparable from the production of subjectivity, being either syntonic or dystonic, according to the mode of production that provides the foundations for its fulfillment. With these elements, a new definition for psychic health is being proposed here as a basis for actions of Psychosocial Care.
\end{abstract}

Uniterms: Social support. Psychotherapy. Health care reform.

Neste ensaio, pretende-se analisar o processo de produção de saúde no contexto da atenção ao sofrimento psíquico, os seus diferentes modos, e as consequências produtivas de cada um deles. Partindo da hipótese de que saúde e subjetividade são indissociáveis, busca-se contribuir com a transformação das práticas no campo da atenção psicossocial que vem sendo implementada no país. Esta análise pretende estar

$\cot$

- Universidade Estadual Paulista Assis, Faculdade de Ciência e Letras, Departamento de Psicologia Clínica. R. Dom Antonio, 2100, Parque Universitário, 19806-900, Assis, SP, Brasil. E-mail: <abiliocr@assis.unesp.br>. 
incluída na série das diferentes pesquisas e estudos teórico-técnicos e éticos que procuram definir tecnologias para uma clínica crítica e ampliada no campo da saúde mental coletiva (Alberti \& Figueiredo, 2006; Amarante, 2007; Lancetti, 2006; Nery \& Costa, 2008; Paim \& Almeida Filho, 2000; Santos, 2009, 1995; Santos \& Costa-Rosa, 2007; Tenório, 2001).

Embora no contexto de uma produção singular, esta não deixa de guardar semelhanças estruturais com a produção comum, a ponto de ser pertinente e proveitoso aplicar-Ihe os referenciais utilizados para análise dos produtos no modo capitalista de produção (Marx, 1898/n.d.). Pode-se, então, tirar conclusões e questões extremamente esclarecedoras quanto à configuração dos modos de produção, aos efeitos produtivos em termos do excedente de produção (mais-valia), aos efeitos da divisão do trabalho e quanto às relações entre produção e apropriação, entre outros aspectos (Fioravante, 1978). Propõe-se, portanto, considerar a instituição de saúde mental como um dispositivo de produção singular.

Um ponto fundamental desta análise passa pela hipótese de que a consistência da saúde que está presente no campo psíquico se expressa sob a materialidade das diferentes formas da subjetividade, implicando que tais aparatos institucionais sejam, antes de tudo, dispositivos de produção de subjetividade e subjetivação. A fisionomia mais relevante do processo de produção saúde-adoecimento-atenção no campo psíquico aparece nas figuras da subjetividade e dos processos de subjetivação.

Outro ponto importante consiste em pensar que a indissociabilidade saúde-subjetividade implica em que os efeitos da produção sejam diretamente decorrentes dos modos de produção sob os quais operam tais instituições. Dessa forma, haverá implicações radicais para os efeitos dessa produção caso a instituição opere na lógica do Modo Capitalista De Produção (MCP) ou segundo a lógica da produção cooperada que o antecedeu (Marx, 1975).

Procura-se demonstrar que não há produção de saúde psíquica no contexto coletivo, sob o vértice da atenção, sem a intermediação da instituição como dispositivo. Em decorrência dessa intermediação necessária, fica a obrigatoriedade de rever as formas do

116 funcionamento institucional a fim de poder driblar suas características atuais, sintônicas com o MCP. Esse é o único modo de garantir condições mínimas para a produção de relações sociais e intersubjetivas singularizadas entre os trabalhadores da instituição, bases imprescindíveis para a construção do mesmo modo de relações com os sujeitos do sofrimento e com a população, preconizadas pela ética da atenção psicossocial.

Analisa-se a instituição a partir da hipótese de que sua configuração atual possa ser mais adequadamente compreendida em termos dos efeitos da luta entre dois paradigmas que se contrapõem neste momento histórico (Kuhn, 1978). Esses paradigmas que configuram os processos de produção na atenção ao sofrimento psíquico são designados como "Paradigma Psiquiátrico Hospitalocêntrico Medicalizador" (PPHM) e "Paradigma Psicossocial" (PPS). Os argumentos em favor dessa designação vêm de suas características e da análise histórica das transformações do campo da saúde mental, conforme demonstrado a seguir.

Com os esclarecimentos conceituais operados neste trabalho, pretende-se deixar mais bem facultadas as possibilidades de fundamentação e realização de uma clínica ampliada na atenção psicossocial, bem como a análise e a avaliação de seus efeitos terapêuticos e ético-políticos.

\section{Gênese}

A instituição de atenção ao sofrimento psíquico, como as demais, é agenciamento das pulsações da demanda social, mediadas pelo imaginário e pela ideologia, numa conjuntura sociopolítica determinada. Utilizam-se aqui os conceitos de demanda social e encomenda social de acordo com sua aplicação no campo da análise institucional (Lourau, 1975). A demanda social é hiância em sentido amplo: conjunto das pulsações produzidas pelos antagonismos das forças em jogo no espaço socioeconômico e cultural. A encomenda é uma espécie de contraface da demanda, ou seja, o modo como esta aparece empiricamente nos pedidos.

Essa conjuntura em que a instituição surge pode ser analisada e compreendida por meio de um importante conceito de Gramsci, transladado da análise política para o campo institucional: processo de estratégia de hegemonia. Por isso, sempre resta na instituição, 
como efeito desse processo de constituição, um não sabido estrutural em relação à demanda social de que ela é efeito. O Processo de Estratégia de Hegemonia $(\mathrm{PEH})$ é um conceito de Gramsci que nos permite analisar, em termos molares, certas linhas de composição das formações sociais: pulsações que as organizam e que nelas se atualizam (Gruppi, 1978). No caso das instituições de saúde mental, isso permite analisar e compreender o jogo de forças que nelas se mostra, contrapondo os aspectos do PPHM aos do PPS, quanto a saberes, práticas, aspectos jurídicos, ideológicos, culturais e éticos (Amarante, 1995; Costa-Rosa, 2000). O PEH compreende um conjunto de práticas relacionadas à estratégia e à tática, destinadas a manter a formação social, seja da instituição seja da sociedade como um todo, em equilíbrio dinâmico, dado tratar-se de realidades segmentares e contraditórias quanto aos interesses e visões de mundo que aí necessariamente se atualizam. Historicamente, essa segmentaridade tende à polarização, daí a possibilidade de falar em PEH como esforço para manter em equilíbrio dinâmico interesses dominantes e subordinados. Do lado dominante, vemos um conjunto de práticas de efeitos repressivos e ideológicos, além de um conjunto de concessões táticas seguidas de sua recuperação (Guattari, 1981). Do lado subordinado, há um conjunto de práticas que são concordes com os interesses do polo socialmente determinante e que os reproduz devido à sua dominância ideológica e material. Entretanto, há também um conjunto de reivindicações, além de um conjunto de práticas alternativas, que às vezes chega a aspirar à elaboração de uma hegemonia alternativa à dominante, ou seja, pode, naquele contexto, consolidarem-se as aspirações de tornar hegemônicos os interesses até então socialmente subordinados. 0 caso das instituições de saúde mental, neste momento histórico, é bastante ilustrativo desse processo: aí se veem os efeitos de uma verdadeira luta pela hegemonia das visões teóricas, técnicas, ideológicas, culturais e éticas. Esse processo, na prática cotidiana, tem gerado o ideário das experiências e as práticas da reforma psiquiátrica em torno dos Centros e Núcleos de Atenção Psicossocial (CAPS e NAPS), como organizadores e realizadores das práticas integrais num determinado território.

Voltemos à análise da conjuntura em que surgem as instituições que são tomadas como foco: as instituições para lidar com os processos associados ao sofrimento psíquico. O mesmo processo que gera a instituição como dispositivo social vai ocorrer com os outros efeitos da demanda social. Portanto, a isso não escapam os efeitos para cuja lida a instituição se considera feita: queixas, pedidos de ajuda, sintomas, crises, conflitos, sofrimento mudo etc. Assim, também os impasses subjetivos e de sofrimento psíquico só se manifestam na distância dada por esse "não sabido" que os constitui, tanto na dimensão subjetiva quanto na sociocultural. A mediação ideológica e imaginária está necessariamente presente nos processos de sua produção e expressão. Eis a razão estrutural das diferentes hermenêuticas. É preciso considerar, ainda, que uma parte importante das pulsações da demanda social pode encarnar-se em indivíduos concretos, sob a forma do sofrimento e das queixas. Nesse caso, tendem a redobrarse os efeitos de alienação (que é simultaneamente social e subjetiva), exigindo, na mesma medida, o redobramento da acuidade dos referenciais de escuta e compreensão utilizados por parte daqueles a quem se dirigem essas queixas e pedidos.

\section{Consistência}

A instituição é articulação de saberes e práticas por um discurso lacunar, como todos os enunciados discursivos. Tomando uma sugestão de Hegel dos três momentos do conceito - universal, particular e singular -, pode-se pensar a instituição como conjunção de esferas ou momentos lógicos articulados (Lourau, 1975).

A esfera dos discursos constitui a instituição como universalidade ou como prática discursiva. Vale observar que há instituições que se mantêm por longo tempo apenas com a consistência de práticas discursivas. Foi assim com a loucura no momento anterior à "Nau dos loucos" e com o movimento antimanicomial antes dos Centros e Núcleos de Atenção Psicossocial (CAPS e NAPS).

Sem menosprezar os efeitos reais das instituições como lógicas na subjetividade, o que nos interessa é especificar os efeitos da instituição sobre um "objeto" quando ela atinge a consistência, designada aqui como "instituição-dispositivo": nau dos loucos, manicômio, discurso médico-psiquiátrico como laço social da psiquiatria como ciência, os CAPS e os NAPS e as outras instituições da atenção psicossocial. 
Há a esfera das práticas que constitui a instituição como particularidade, onde a instituição se mostra claramente como dispositivo: na realidade, conjunto de saberes e práticas; aquilo que se manifesta de imediato ao observador como um aparelho capaz de determinadas funções, como, por exemplo, tratar os loucos ou educar as crianças, produzir "valores de uso". A esfera da prática é considerada âmbito da negatividade produtiva por sua capacidade de fazer revelar no discurso institucional, pretensamente universal, sua polissemia e suas lacunas de sentido. A prática e os saberes, por sua consistência multifacetada, expressam a riqueza do agir humano, para muito além de qualquer enunciado discursivo que pretenda circunscrevê-lo como unívoco. Práticas e saberes podem superar dialeticamente a si próprios e ao discurso, descartando-o ou elevando-o a outras características discursivas. Pode-se ver esse processo de superação expresso na passagem do discurso "manicomial" ao da reforma psiquiátrica e do discurso desta ao da atenção psicossocial.

É preciso, ainda, pensar a esfera da instituição como singularidade. Esse momento corresponde à articulação dialética do universal e do particular: a práxis. Em sentido geral, tanto o universal quanto o particular são sempre abstratos por sua aspiração à completude. Algumas vezes uma dimensão explicita claramente a intenção de excluir a outra, ou seja, as contradições institucionais podem chegar a ser vivenciadas de forma distorcida, como conflitos entre discurso e prática, ou entre saber e prática, "ou o discurso ou as práticas": momentos confusos para o conjunto dos atores institucionais em que prevalece a reprodução do instituído como se fosse possível haver qualquer prática sem saber associado, ou qualquer saber sem prática que o sustente. Manifestação clara da cisão presente na formação social ampla é a separação entre trabalho braçal e intelectual ou trabalho decisório e executor.

Na dimensão singular do dispositivo, terceiro momento lógico, pode-se ver que o significante "instituição" é polissêmico. É possível recortar três sentidos fundamentais: a instituição como lógica, substantivo, precipitado dos costumes desde tempos imemoriais que pode ser vivenciada como criação mítica, desde sempre e para sempre instituída. Depois, instituição como ato de instituir, ação imediata, verbo, aquilo que

118 é sempre vivo, o aspecto que mais perceptivelmente se encarna na ação dos homens; por exemplo, ao diagnosticar o sofrimento psíquico como loucura, outro radical da razão, está-se, na realidade, instituindo a loucura como outro radical da razão. Considera-se que é na dimensão da instituição como verbo que se pode tanto reproduzi-la como lógica estabelecida quanto recriá-la, introduzindo transformações radicais nessa lógica.

Finalmente, é preciso considerar o sentido da instituição como formação social encarnada em dispositivo de produção social, em que o substantivo e o verbo aparecem como amálgama. Pode-se dizer que o sentido do termo instituição que a análise institucional elevou à categoria de conceito, designa um dispositivo de "instituir" o instituído (reprodução) e o instituinte (criação). É esse conjunto composto por arquitetura, mobiliário, maquinário, saberes e práticas segmentares articulados por um discurso que estamos definindo como dispositivo institucional, que opera sobre "objetos" configurados e em função de objetivos determinados no contexto de uma realidade social complexa capaz de expressar-se em processos produtivos e modos de produção.

\section{Funcionamento}

A consideração desses três momentos, também desdobrados em âmbitos articulados, permite tirar as maiores consequências da definição da instituição como conjunto de saberes e práticas articuladas por um discurso de tipo ideológico (Luz, 1979; La Passade, 1971).

Essa definição de instituição implica duas consequências: a instituição consistir numa formação social que é articulação de contrários, e considerar-se nela a existência de uma ordem latente, para além da ordem manifesta.

A primeira consequência nos remete à observação de que a instituição articula um conjunto de interesses, cuja segmentaridade pode variar desde simplesmente diferentes a contraditórios. Diversidade em termos das visões de mundo em jogo e dos efeitos de suas ações diretamente sobre seus "usuários", mesmo que tudo aparentemente seja consenso (neste estudo propõe-se a substituição dos termos "paciente" e "usuário" por "sujeito do tratamento ou do sofrimento", conservando a ambiguidade da palavra sujeito). A diversidade pode chegar à polarização e desdobrar-se 
em lutas pela hegemonia de uns ou outros interesses e valores.

Da segunda consequência pode-se concluir que é sempre necessária alguma hermenêutica, algum exercício de deciframento para alcançar o sentido de seu discurso e de suas práticas. Nesse exercício de interpretação, deve-se sublinhar a importância a ser dada à análise do enunciado discursivo, dada sua prevalência como autoapresentação da instituição. Enuncia-a sempre como positividade: "o que ela é" ou pretende ser. Outra etapa dessa operação de decifração toma como foco a relação e o confronto das práticas institucionais com o discurso. Aí o foco cabe às práticas, conforme assinalado anteriormente, pois elas são capazes de revelar não só as contradições do discurso institucional como também uma face de produção de saber novo. Em outras palavras, elas contêm potencialmente a dimensão da práxis.

A partir dessas duas consequências da definição de instituição - como articulação de saberes e práticas por um discurso -, pode-se arriscar uma hipótese referente às exigências de sua compreensão por quem trabalha nelas, ou seja, pelos trabalhadores como um de seus componentes estruturais: a análise das contradições que atravessam a instituição e mais amplamente o manejo de um referencial de análise de discurso são ferramentas imprescindíveis para quem deseja inserir-se numa instituição de um modo não apenas funcionalista. É importante frisar que isso ainda não tem qualquer relação com "ser um" analista institucional (Altoé, 2004); falando dialeticamente, significa propor a hipótese de que os trabalhadores podem ser a parte da instituição através da qual ela pode tomar certa consciência de si e para si.

\section{Análise das contradições}

Ao conceber o dispositivo institucional de atenção ao sofrimento psíquico como segmentar, quanto às forças que o compõem e nele se articulam, funda-se a pertinência de uma análise das contradições capaz de indicar o estado dos conflitos que aí se atualizam e metabolizam em relação à demanda social de que a instituição é efeito. Esse estado do jogo de forças em ação na instituição pode ser esclarecido pela especificação das suas principais contradições, pela distin- ção entre contradição principal e as secundárias, e pela compreensão dos antagonismos decorrentes das diferenças essenciais entre saberes e práticas em relação ao discurso. O estado das contradições pode ser indicado, ainda, pela análise da proporção de força estimada de cada um dos pólos de interesse presentes naquela conjuntura particular, naquele momento. No exemplo das instituições de saúde mental de nosso contexto político-social atual, é possível afirmar a hipótese de que a contradição essencial se expressa em termos de dois paradigmas básicos, configurados e diferenciados pelos modos de organização de seus parâmetros constitutivos, de suas funções produtivas e de seus modos de produção: PPHM e PPS.

O PPHM conjuga interesses básicos de um setor social: suas opiniões, suas concepções ideológicas e teórico-técnicas, sua ética, seus ideais socioculturais, seus interesses econômicos e sua forma dominante de produção de saúde e de subjetividade. Por sua predominância quantitativa, e por ser ele que ainda continua imprimindo a fisionomia característica das instituições de saúde mental em nosso meio, não podemos ter dúvida quanto a considerá-lo o paradigma dominante; portanto, ele conjuga, na instituição como dispositivo, os interesses identificados com os interesses socialmente dominantes. O nome "psiquiátrico hospitalocêntrico medicalizador" pode ser atribuído à sua origem na psiquiatria como medicina mental e ao fato de que o hospital psiquiátrico ainda seja o meio de ação que melhor o representa, mesmo que há bastante tempo não seja o único. Na realidade, os meios do hospital estão sendo substituídos pelos da química. Os termos que designam o paradigma devem, ainda, ser remetidos à estrutura das relações sociais e intersubjetivas fundadas no laço social do "Discurso Médico" carreado pela psiquiatria (Clavreul, 1983), e à utilização contemporânea da medicação como resposta a priori para os impasses do sofrimento psíquico (Tenório, 2000). "Medicalizador" é um significante que condensa o radical "med", referente ao laço comum médico-paciente e ao medicamento, como seu meio universal de ação.

Nas diferentes críticas e ações democratizantes de que tem sido alvo, principalmente a partir da segunda metade do século XX, o PPHM tem-se feito acompanhar de um amplo cortejo de discursos e práticas de natureza diversa; alguns até mesmo de outra consistência para- 
digmática. Essas composições, entretanto, raramente têm passado de seus auxiliares secundários.

Recentemente, há casos em que esses discursos, saberes e práticas têm produzido ranhuras importantes, embora localizadas, em sua hegemonia. Essas transformações têm sido analisadas sob o prisma da alternatividade paradigmática. O paradigma que se contrapõe ao psiquiátrico tem sido designado com vários títulos, a depender dos momentos e contextos históricos em que é exercido: "práticas alternativas à psiquiatria","reforma psiquiátrica", "atenção psicossocial". O fundamental é considerar que esse conjunto de ações configura-se, neste momento histórico, como um paradigma dialeticamente alternativo, enunciação de outra forma possível de hegemonia no campo da atenção ao sofrimento psíquico (Costa-Rosa, 2000).

Um dos aspectos que definem radicalmente sua alternatividade é o fato de ele conjugar os interesses básicos de outro grupo social presente nessas instituições. Esse bloco de interesses tem estado historicamente identificado com os interesses dos chamados usuários, na realidade os verdadeiros sujeitos das instituições. Neste estudo, propõe-se a substituição dos termos "paciente" e "usuário" por "sujeito do tratamento ou do sofrimento", conservando a ambiguidade da palavra sujeito.

O PPS procura uma relação muito mais direta com as pulsações instituintes veiculadas por esses sujeitos e seu contexto histórico, assim como com os interesses dos trabalhadores, do que com os interesses instituídos e veiculados pelo PPHM. A lógica paradigmática do PPS - expressa por concepções teóricas, técnicas, ideológicas e éticas -, seus ideais, e os interesses a que visa são contraditórios com os do PPHM.

A partir de uma análise do estado global do jogo de forças no campo da saúde mental, no contexto brasileiro, não é difícil demonstrar que, no momento atual, o bloco de interesses que se conjuga no PPS ainda é subordinado em relação ao bloco conjugado no PPHM, embora devamos notar que ele está bastante bem configurado no ideário e já se expresse no exercício de um conjunto de práticas bastante significativo e crescente: centros e núcleos de atenção psicossocial, oficinas e cooperativas, residências autogeridas, entre outras, que são componentes importantes da política oficial do Ministério da Saúde para o setor (Brasil, 2004). Os "interesses" dos sujeitos do sofrimento têm papel secundário no PPHM, pois nesse modo de organizar a instituição e em seus processos produtivos prevalecem os objetivos de realização da mais-valia, tal como ela ocorre na produção comum, e da reprodução das relações sociais e intersubjetivas típicas dessa produção (subjetividade serializada).

Já há alguns anos tem sido proposta a denominação de modo psicossocial para o conjunto de práticas que compõem o paradigma alternativo, que se propõe a ser substitutivo ao paradigma psiquiátrico hospitalocêntrico medicalizador (Costa-Rosa, 1992, 2000; Costa-Rosa, Luzio \& Yasui, 2003). Uma das razões principais dessa denominação decorre de ele ter incorporado uma série de concepções de outros campos de saber, como o materialismo histórico, a psicanálise, a psicologia social e as ciências sociais, e da própria filosofia, além das contribuições originadas diretamente das experiências "alternativas à psiquiatria" (Fleming, 1976). Essas influências permitem que ele se proponha a considerar os fatores psíquicos e socioculturais como essenciais, tanto na configuração dos problemas quanto na confecção dos meios de sua resolução, sem excluir possíveis aspectos orgânicos e a utilização da medicação, contanto que subordinada a sua lógica paradigmática. Outra razão importante dessa denominação decorreu do fato de que os primeiros dispositivos para tratamento do sofrimento psíquico, alternativos ao PPHM, implantados em São Paulo em meados da década de 80, foram associados ao significante "psicossocial": Centros de Atenção Psicossocial e Núcleos de Apoio Psicossocial (Costa-Rosa et al., 2003). Uma análise mais detalhada desses dois paradigmas não terá dificuldades em demonstrar que a natureza da produção e dos produtos que está em jogo em cada um deles é radicalmente diferente, a ponto de poderem ser considerados alternativos no sentido dialético.

Cada um desses paradigmas imprime direções contraditórias para a teoria, a técnica e a ética, determinando, em consequência, modos antagônicos de produção de subjetividade e realizando diferencialmente a relação entre produção de subjetividade e "produção de saúde", cujos efeitos, para o sujeito que recorre à ajuda psíquica, são também antagônicos em termos terapêuticos e éticos. Em um caso, tem-se a produção de saúde psíquica associada à produção de subjeti- 
vidade capitalística (serializada); no outro, a saúde produzida busca a consistência da subjetividade singularizada (Guattari \& Rolnik, 1986).

É necessário sublinhar que falar em produção de saúde em termos de produção de subjetividade não é incompatível com o fato de se priorizar neste trabalho a dimensão molar do dispositivo institucional, que não é tomado como situado num plano de transcendência. Na própria concepção da gênese da instituição, anteriormente expressa (efeito de pulsações), está posta a hipótese de uma simultânea concepção molar e rizomática, que abrange, portanto, também os processos micropolíticos. Apenas os objetivos imediatos neste trabalho convidam a pôr em foco a dimensão molar, ou seja, a necessidade de fazer uma análise paradigmática dos processos de produção de saúde e subjetividade, e apresentá-la de forma clara e sintética aos participantes diretos dessas instituições. Os processos moleculares, microfísicos, são considerados fundamentais, e até mesmo imprescindíveis, quando se opera em intercessões nas instituições por meio dos referenciais da análise institucional (Guattari, 1981; Lourau, 1975; La Passade, 1971). A análise institucional nessa vertente teórica nada mais é que uma intercessão no plano institucional de imanência. Entretanto, o estudo dos planos moleculares pode funcionar como uma bússola imprescindível da ação micropolítica.

\section{As funções produtivas das instituições de saúde mental}

Dada a natureza de um discurso ideológico - formação linguageira, enunciado de aspiração totalizante-, e sua função de articular os saberes e práticas contraditórios presentes na instituição, é inevitável que ele acabe por explicitar apenas as funções positivas do dispositivo institucional como formação social particular. Desse modo, uma interpretação desse discurso levando em conta suas lacunas, e das suas relações com os saberes e as práticas presentes na instituição, pode permitir o acesso a outras funções institucionais, a princípio veladas ou apenas não designadas.

Depois de uma análise da instituição típica para tratamento do sofrimento psíquico, que neste momento histórico assume várias fisionomias, como hospital psiquiátrico, ambulatório de saúde mental, centro de atenção psicossocial e núcleo de atenção psicossocial, encontram-se as seguintes funções bem delimitadas: uma função positiva, que se expressa no discurso institucional como função oficial - atenuar ou remover sofrimento e sintomas, proteger o indivíduo e a sociedade dos efeitos do sofrimento psíquico, reintegrar socialmente os indivíduos, curar, entre outros termos; - e uma função negativa, que, na realidade, se subdivide em três.

A primeira subfunção negativa consiste na produção de "mais-valia", a exemplo das instituições da produção comum. Mais especificamente deve-se considerar que as instituições de saúde mental atuam na realização do excedente produzido pelo trabalho nas instituições químico-farmacêuticas, hospitalares e editoriais, por meio da utilização dos seus produtos. É importante não menosprezar a importância dessa função como fator determinante das características da ação do dispositivo institucional sobre seu "objeto". Nessa função, expressa-se uma característica fundamental das instituições organizadas segundo o modo capitalista de produção (Marx, 1975): tendência à sintonia entre ideologia dominante e tecnologia dominante. Essa sintonia está absolutamente evidente entre as concepções do sofrimento psíquico do PPHM e os avanços tecnológicos da indústria químico-farmacêutica, e, mesmo nas práticas da psiquiatria dita reformada, ela não deixa de se manter.

A segunda subfunção negativa merece o maior destaque pela natureza dos efeitos que produz. Trata-se da reprodução das relações sociais e intersubjetivas dominantes, ou seja, as mesmas relações sociais da produção de mais-valia no campo social, basicamente relações verticais de domínio e subordinação. Parece simples, entretanto pode-se considerar que é por meio dessa função institucional que se opera uma das formas da produção dessas instituições que é mais letal aos interesses dos sujeitos do sofrimento e dos próprios trabalhadores nas práticas da saúde mental coletiva: sabotagem das dimensões criativas dos sintomas e das crises, e do próprio trabalho dos agentes institucionais. Hipótese decorrente: é a dominância dessa função (re)produtiva que define mais fundamentalmente a consistência do PPHM neste momento histórico; dito de outro modo, a modalidade de produção de subjetividade serializada ou subjetividade capitalística dá ao modo de produção das instituições de saúde mental 
sua maior sintonia com a lógica do MCP. Não é difícil demonstrar que no PPHM, que está muito longe de ser patrimônio exclusivo dos psiquiatras, há a produção de um excedente do ato produtivo que tem as características da mais-valia, sob uma forma peculiar, cuja "apropriação" também é feita pelos "interesses dominantes". Ou seja, ao produzir o "produto" nomeado positivamente no discurso da instituição (saúde, cura, adaptação), reproduz-se uma forma de subjetividade que é a própria reprodução das relações sociais dominantes: relações sociais sapientes-ignorantes, supridoscarentes, dominantes-subordinados, mandantes-obedientes, loucos-sãos, trabalhadores-usuários; para não falar na reduplicação tautológica dos significantes dos sintomas por meio dos códigos usados pela psiquiatria medicalizadora. Uma análise mais aprofundada dessa função institucional pode ser realizada a partir da aplicação da teoria dos discursos como laços sociais, de Jacques Lacan (Clavreul, 1983; Lacan, 1992), deixando ainda mais evidente os efeitos iatrogênicos do ato de "produzir saúde psíquica" por meio de laços sociais caracterizados por relações de produção dessa natureza.

A terceira subfunção negativa é a mais cara aos interesses subordinados na instituição de saúde mental também devido à natureza de seus efeitos. Trata-se da capacidade que têm as instituições, decorrente da segmentaridade das pulsações que as constituem e as organizam, de se contraporem, através de suas práticas, às relações sociais estabelecidas, exercitando a possibilidade de outras formas de relação: especialmente formas novas relacionadas à dimensão instituinte, necessariamente presente no sofrimento e nos impasses que "quer se tratar". Essas novas formas de relação podem ou não chegar a ser referidas no discurso, porém seu primeiro âmbito de ocorrência é o das práticas, e mesmo dos saberes. Às vezes as exigências de novas práticas e novos modos de relação com os sujeitos do sofrimento decorrem de necessidades espontâneas, como é o caso da persistência do sofrimento para além de todas as ações terapêuticas oficiais da instituição; porém a recriação das relações interinstitucionais e "intersubjetivas está relacionada às pulsações desejantes dos trabalhadores, à própria dimensão autopoiética do trabalho humano.

Trata-se, sinteticamente, da manifestação de 122 demandas de produção da diferença, a partir daquilo que, da demanda social, sempre se expressa como exigência de novidade. Demanda social é hiância decorrente das múltiplas pulsações que constituíram e constituem a própria instituição. Outras vezes essas formas novas de relações sociais e intersubjetivas se dão já a partir de exigências decorrentes de outras contribuições que historicamente se contrapõem de modo explícito ao instituído. É o caso, num dado momento histórico, das contribuições baseadas nas técnicas e éticas da psicoterapia institucional, antipsiquiatria, da psicanálise, do materialismo histórico, da psiquiatria democrática, entre outras (Fleming, 1976; Lourau, 1975). Nesse exercício de novas formas de relação social e intersubjetiva, encontra-se a forma da produção mais cara, uma espécie de capital-ouro da práxis, capaz de se contrapor à do PPHM, ainda dominante. Pode-se designá-la como produção de subjetividade singularizada, por partir dos sujeitos do sofrimento e trabalhadores que assumem seus lugares de agentes produtivos por excelência.

Dessa terceira função negativa depende a possibilidade da instituição se transformar na direção dos interesses mais genuínos de que ela é um efeito no processo de estratégia de hegemonia: trata-se de algo que escapa à mediação ideológica. Pode-se demonstrar que há igualmente a produção de um excedente do ato produtivo em saúde, do qual só podem apropriar-se os indivíduos diretamente interessados, isto é, os sujeitos identificados como "usuários", os trabalhadores e a população do território. É no próprio ato de produção de um laço social que se opõe dialeticamente ao discurso médico no PPHM, que se pode dar a apropriação do saber novo produzido. Esse laço social põe em ação relações sociais e intersubjetivas horizontais, base necessária para o protagonismo da produção-apropriação desse saber. Na realidade, nessa terceira subfunção institucional, redefinem-se o processo de produção e o modo de produção, que já não aceita qualquer cisão entre quem produz e os meios e fins da produção, e entre os atos produtores e os atos de apropriação daquilo que é produzido. Essa função institucional também demonstra cabalmente que quando se trata do sofrimento psíquico não se pode fazer disjunção entre "produção de saúde" e produção de subjetividade.

Essas teses são suficientes para justificar a colocação de algumas questões essenciais decorrentes da 
singularidade do campo de produção em saúde psíquica: quem é o produtor essencial? Qual a especificidade do processo de produção (relações entre meios, fins, "produto", excedente produtivo, modos de apropriação)? Qual o limite da separação entre fazer e pensar, nesse contexto? Entre outras. Algumas dessas questões podem ser desdobradas para o contexto geral das práticas em saúde, dado que essas subsumem também a dimensão psíquica e subjetiva.

\section{A instituição é um intermediário necessário}

\section{A forma da sua intermediação é contingente}

Tal como na produção em geral, a questão crucial para as práticas de atenção ao sofrimento psíquico em nosso contexto e momento históricos é a separação entre o trabalhador e os meios/instrumentos da produção. Os trabalhadores, para produzirem, também têm que se recombinar com os meios de trabalho. Para isso, porém, precisam apelar para um intermediário que é dono dos meios de produção e remunerador direto da força de trabalho. Apesar da especificidade do campo da atenção ao sofrimento psíquico como setor produtivo, e da singularidade dos seus "produtos" - "subjetividades/saúde" -, a lógica geral pela qual ele se rege, em uma de suas modalidades dominantes, é a do modo capitalista de produção.

Como caracterizar esse modo de produção a que Marx chama capitalista ou burguês moderno? Pela comparação com os modos de produção que o antecedem, vê-se de imediato que há uma separação entre a força de trabalho e os demais meios de produção; trabalho e condições objetivas de trabalho aparecem agora como pertencentes a diferentes proprietários. Em resumo, o trabalhador ainda é o dono da força de trabalho, mas já não é proprietário dos outros meios de produção. No caso do trabalho em saúde mental, em princípio, estritamente desse ponto de vista, é possível notar que as condições objetivas incluem também as próprias "condições subjetivas" (formação e psicoterapia), que são objetivadas como meios comuns do trabalho, e, às vezes, remetidas à incumbência do intermediário, que comumente não as reconhece desse modo, instalando-se uma espécie de alienação do trabalhador, que lhe custa muito caro, e mais, ainda, da população que utiliza a instituição. Pode-se ver também que a cooperação e a divisão social do trabalho se organizam em prol de uma produção que já não visa apenas à produção de "valores-de-uso". Ao contrário, é a outra dimensão dos produtos elucidada por Marx (1898/n.d.), o valor de troca, que faz a sua razão de ser.

No MCP já não é o consumo em si que é a razão de ser da produção, mas a troca, pois é através dela que se drena para "o capital", proprietário dos meios de produção, o excedente da produção gerado pelo trabalho (mais-valia). O excedente produzido, criado pela força de trabalho acima do necessário, já não é mais objeto da apropriação coletiva, mas apenas de um dos polos de interesses presentes no campo social e no processo de produção. A análise mais ampla de Marx consiste em mostrar que nessas transformações sociais de que resulta o MCP, destaca-se a separação entre proprietários da força de trabalho (o trabalho) e proprietários dos meios de produção (o capital); já foi indicado como essa característica marca de forma drástica a natureza do modo de produção e da relação dos produtores com o produto do seu trabalho no campo da saúde, alterando radicalmente o próprio processo de produção e seus efeitos produtivos, sobretudo as relações de apropriação.

Em relação à análise do intermediador necessário, quando se trata da saúde coletiva é o Estado que assume as feições da própria instituição, ou seja, esta o encarna e o representa na intermediação entre trabalhadores e"usuários" de seus serviços. A instituição, portanto, pode ser organizada segundo dois modos distintos de produzir e tem várias funções produtivas, capazes de se atualizarem simultaneamente em cada ato de produção.

Essa intermediação necessária faz com que não haja ato produtivo puro. A inextricabilidade entre ato de produção e ato de "consumo do produto", no campo da atenção ao sofrimento psíquico, faz com que aí a "produção" seja altamente sensível às formas da intermediação. Daí a proposição de que a forma da organização da instituição como dispositivo deva ser um foco particularmente importante de cuidado na consideração do processo de produção em questão. Se a instituição se organiza segundo as características do MCP ou segundo uma forma capaz de driblar os efeitos desse modo de produção (através dos modos cooperados, cogeridos e autogeridos), isso será decisivo para a resultante dos seus atos produtivos. Mudarão radicalmente em um caso e em outro a natureza da produção, dos "produtos", 
do excedente produtivo, quem dele se apropria e de que forma.

A hipótese que se pretende demonstrar neste trabalho, dada a intermediação necessária da instituição nas práticas de atenção ao sofrimento psíquico, é a de que a produção e o "produto" que interessam aos sujeitos da instituição, à população e aos trabalhadores, supõem a neutralização das características de MCP sob a qual se organizam esses dispositivos institucionais no PPHM; ou seja, não se pode excluir o intermediário, mas pode-se transformar radicalmente a forma da intermediação. O que autoriza essa hipótese é o fato de estarmos no campo da saúde, onde, por economia de complexos desdobramentos históricos e teóricos, a própria realidade desse campo dá o apoio necessário para trabalhar na direção dessa hipótese. Os movimentos sociais que têm lutado pala ampliação e transformação do campo da saúde, encarnados na reforma sanitária e na reforma psiquiátrica, não têm deixado escapar esse aspecto. A participação direta da população no planejamento, na gestão e no controle através dos conselhos de saúde, conselhos de cogestão dos dispositivos institucionais, e associações de "usuários" e familiares, permite justamente a transformação do modo das relações intrainstitucionais na direção oposta ao funcionamento das instituições características do MCP: de heterogestão para cogestão e autogestão. A neutralização do MCP, como forma de intermediação nos atos de produção de saúde psíquica, deverá passar pela superação das relações sociais intrainstitucionais verticais e sua substituição por processos cooperados de gestão do dispositivo e do processo de trabalho, como bases imprescindíveis para a produção da subjetividade singularizada.

\section{Considerações Finais}

A instituição em questão é uma formação social surgida em determinado momento histórico para "responder" a efeitos específicos da demanda social, ou seja, pulsações determinadas ou fortemente influenciadas pelas pulsações e pelas contradições presentes na própria sociedade. Essas pulsações foram primeiramente filtradas, nas sociedades ocidentais, sob a perspectiva da loucura redefinida como doença mental seguindo os padrões vigentes da prática médica na época. Historicamente, essa instituição assume várias fisionomias

124 que revelam longevidade e capacidade de sobreviver e conviver. Nossa análise visou mostrar que a aparente diversidade, quanto ao essencial, pode ser sintetizada em duas modalidades paradigmáticas básicas, sobretudo considerando como foco suas funções sociais produtivas. Como formações sociais complexas, essas instituições são caracterizadas pela segmentaridade quanto a valores e interesses sociais que conjugam, e quanto às funções com que veiculam a realização deles. Essa segmentaridade desdobra-se por meio de uma superposição de funções dentro de cada dispositivo e mesmo dentro de um único ato produtivo. Essa hermenêutica a que submetemos a instituição, claramente distinta de uma análise institucional (Altoé, 2004; Lourau, 1975), permitiu distinguir aspectos que in vivo nem sempre estão claramente presentes.

Visando a esclarecer alguns aspectos dos componentes do processo de produção nesse contexto, suas modalidades e suas consequências, em termos terapêuticos e éticos, designaram-se dois paradigmas principais que, rigorosamente, já estão presentes desde a gênese dessas instituições, embora em composições e arranjos bastante diferenciados conforme o momento e o contexto histórico. Em suas configurações atuais, pode-se nomeá-los "paradigma psiquiátrico hospitalocêntrico medicalizador"e "paradigma psicossocial", por razões ao menos sinteticamente fundamentadas. Autoriza-se propor a síntese dessa variabilidade em termos de dois paradigmas a partir de nosso método de análise, mas é também um componente de nossa tática de trabalhador do campo: a ética que preside a nossa pesquisa e análise crítica das instituições de saúde mental não se alinha a qualquer tese sobre a neutralidade do conhecimento.

Procurou-se indicar que os diferentes modos de produção são de consequências radicalmente diferentes em termos sociais e para os sujeitos dessas instituições: trabalhadores e "usuários", tanto em termos dos efeitos terapêuticos de suas práticas quanto das implicações éticas desses efeitos. Como se manifesta a clássica iatrogenia das práticas terapêuticas nesse campo?; que soluções são dadas aos impasses?; considera-se ou não a relação destes com os contextos sociais, familiares e subjetivos dos indivíduos e grupos?; os efeitos dessas práticas contentam-se com a adaptação ou permitem aos indivíduos algum deslocamento nas/das conjunturas conflitivas e contraditórias em que se produzem e revelam esses "males"? 


\section{Organizando o raciocínio em forma de teses}

Tese um: o PPHM é corolário necessário do MCP, o que se revela pela disjunção, dessintonia entre saúde psíquica e subjetividade, isto é, concebe a possibilidade de um sujeito simultaneamente saudável e alienado. Pode-se dizer também que pretende interferir nos processos de subjetivação fazendo curto-circuito da subjetividade.

Tese dois: as relações intrainstitucionais são necessariamente transladadas para as relações da instituição com os "usuários" e a população. Algumas das razões desse fato são imaginárias (repetição de vínculos organizadores da visão de mundo e repetição do recalcado como forma de transferir suas afetações para o outro), outras têm consistência real, são estruturais, dependem da congruência necessária entre a forma de organização do dispositivo de produção e o modo do processo de produção por ele e nele empreendido.

Tese três: produzir saúde psíquica é também produzir subjetividade - operar em relações subjetivas e simultaneamente através delas. Ou seja, não se podem dissociar "produto" e seu modo de produção sem cair em aberrações como a de supor a produção de saúde dissociada de sua apropriação. Isso é possível e legítimo apenas para o PPHM.

Tese quatro: a definição de saúde psíquica que interessa aos "usuários" e aos trabalhadores, sujeitos das instituições, expressa no paradigma psicossocial, exige sintonia entre o modo de produção de saúde e o modo de produção de subjetividade.

Tese cinco: a sintonia só pode ser almejada na base da superação de hierarquias de poder e saber neutralização das ofertas "autoritárias" e carismáticas de possibilidades de transferência, só assim estarão criadas as condições para a "crítica", por parte dos trabalhadores da instituição, das suposições imaginárias da população usuária, que regem as formas iniciais dos vínculos (inter)subjetivos e de transferência de saber. Suposições de que existe um grande outro supridor, isto é, de que aquilo de que se necessita e se deseja é realizável em termos de suprimentos medicamentosos, suprimentos de saber, de poder ou sob quaisquer outras formas.

Tese seis: A meta ética da clínica ampliada na atenção psicossocial não dá margem a quaisquer dúvidas a respeito da necessidade de superação das relações intrainstitucionais verticalizadas do dispositivo institucional que sempre opera como intermediário: de relações verticais para relações horizontais/transversais, de relações capitalísticas para relações cooperadas, de relações de mestria para relações de parceria na busca do saber e do poder, de relações com o saber enciclopédico para relações com o saber do sujeito e de sujeito ("não sabido" e inconsciente).

Apesar das transformações no ideário e na legislação operadas pelos movimentos sociais no campo da saúde, a forma dominante atual das instituições de saúde mental, como intermediário, ainda é a do MCP. Essa forma de organização está em sintonia com as características do PPHM, cujo efeito é produção de saúde como "reposição de suprimentos" e como produção (inadvertida?) de subjetividade serializada. Ou seja, onde domina o MCP predomina o PPHM. Sob esse prisma, pode-se ver mais um aspecto sutil do "mandato social" de que tanto se tem criticado a psiquiatria.

O paradigma psicossocial supõe o avanço na superação das características do MCP presentes no dispositivo institucional, deslocando para seu lugar um modo do processo de produção capaz de superar seus efeitos principais, instalando a organização do dispositivo institucional e a produção em moldes cooperados.

Por não distinguir saúde psíquica de subjetividade, sua definição de saúde deve coincidir com a de produção da subjetividade singularizada. Essa produção ainda é uma ocupação das brechas abertas no modo hegemônico, e, por constituir estruturalmente o excedente revolucionário do ato produtivo das instituições de saúde mental, deve ser considerada o capital-ouro dos interesses dos sujeitos do sofrimento e dos trabalhadores, também sujeitos da instituição.

A produção de subjetividade singularizada deve ser entendida concretamente e não como quimera em mundos transcendentes. A saúde psíquica não mais se define como um estado, mas como um processo, e mais especificamente como um processo de produção de subjetividade e de subjetivação. Não se trata de um processo de produção sobre os sujeitos do sofrimento, mas um processo de produção no qual eles são participantes diretos, e protagonistas. A partir disso, não há tanta dificuldade em compreender que produção de subjetividade singularizada envolve um processo, certamente difícil e complexo, de estar implicado subjetivamente e socialmente nos conflitos e contradições que 
se atravessam, e pelos quais se é atravessado. Essa implicação resulta necessariamente que se deixe de ser apenas objeto de um assujeitamento que gera sofrimento em excesso para tornar-se um sujeito capaz de produzir deslocamentos nesses impasses e no posicionamento ocupado na relação com eles. Para isso o sujeito deve ser concebido muito além do indivíduo: homem que constrói seu cotidiano a partir de condições dadas, e também sujeito do sentido, sujeito do inconsciente.

No paradigma psicossocial não se deve conceber o excesso de sofrimento, que se encarna em pedidos de ajuda, como o único nem o mais importante componente da demanda social. Sua dimensão instituinte, veiculada nos pedidos de ajuda e expressa no sofrimento, é um dos componentes essenciais a serem (re)recuperados para a "saúde" que interessa produzir aos sujeitos dessas instituições. Ou seja, não se deve esquecer a dimensão "crítica" das crises. Se toda a crise critica o contexto em que ela ocorre, parte dela deve pretender operar como vetor que visa a transformações capazes de retornarem sobre o contexto, por mais difícil, até inicialmente impensável, que isso seja. Deve-se compreender, portanto, que o reposicionamento do sujeito, que colocamos no cerne de nossa definição de saúde psíquica, envolve ações que estão muito além dos sujeitos diretamente identificados pelas crises - ações setoriais, intersetoriais, trans-setoriais; intersubjetivas e trans-subjetivas.

\section{Referências}

Alberti, S., \& Figueiredo, A. C. (Org.) (2006). Psicanálise e saúde mental, uma aposta. Rio de Janeiro: Companhia de Freud.

Altoé, S. (Org.) (2004). René Lourau, analista institucional em tempo integral. São Paulo: Hucitec.

Amarante, P. (1995). Loucos pela vida: trajetória da reforma psiquiátrica no Brasil. Rio de Janeiro: Fiocruz.

Amarante, P. (2007). Saúde mental e atenção psicossocial. Rio de Janeiro: Fiocruz.

Brasil. Ministério da Saúde. (2004). Saúde mental no SUS: os centros de atenção psicossocial. Brasília: MS.

Clavreul, J. (1983). A ordem médica: poder e impotência do discurso médico. São Paulo: Brasiliense.

Costa-Rosa, A. (1992). A essência das práticas em saúde mental alternativas ao Modelo Asilar: o modelo psicossocial. Resumos de Comunicações Científicas do ll Congresso de Psicologia de São Paulo (Vol. 1, pp.248-252). São Paulo:
Costa-Rosa, A. (2000). O Modo psicossocial: um paradigma das práticas substitutivas ao modo asilar. In P. Amarante (Org.), Ensaios: subjetividade, saúde mental, sociedade (pp.141-168). Rio de Janeiro: Fiocruz.

Costa-Rosa, A., Luzio, C. A., \& Yassui, S. (2003). Atenção psicossocial: rumo a um novo paradigma em saúde mental coletiva. In P. Amarante (Org.), Archivos de saúde mental e atenção psicossocial (pp.13-41). Rio de Janeiro: Nau.

Fioravante, E. (1978). Modo de produção, formação social e processo de trabalho. In E. Fioravante, E. Vargas, M. Godelier, S. Dvitçioglu, S. Stuchevski, L. Vasiliev, et al. (Orgs.), Conceito de modo de produção (pp.31-45). Rio de Janeiro: Paz e Terra.

Fleming, M. (1976). Ideologias e práticas psiquiátricas. Porto: Afrontamento.

Gruppi, L. (1978). O conceito de hegemonia em Gramsci. Rio de Janeiro: Graal.

Guattari, F. (1981). Revolução molecular:pulsações políticas do desejo. São Paulo: Brasiliense.

Guattari, F., \& Rolnik, S. (1986). Micropolítica, cartografias do desejo. Petrópolis: Vozes.

Kuhn, T. S. (1978). A estrutura das revoluções científicas. São Paulo: Perspectiva.

La Passade, G. (1971). El analizador y el analista. Barcelona: Gediza S/A.

Lacan, J. (1992). OSeminário: o avesso da psicanálise (Livro 17). Rio de Janeiro: Jorge Zahar.

Lancetti, A. (2006). Clínica peripatética. Rio de Janeiro: Hucitec.

Lourau, R. (1975). Análise institucional. Petrópolis: Vozes.

Luz, M. T. (1979). As Instituições médicas no Brasil. Rio de Janeiro: Graal.

Marx, K. (1975). Formações econômicas pré-capitalistas. Rio de Janeiro: Paz e Terra.

Marx, K. (n.d.). O capital (Vol. 1). Rio de Janeiro: Civilização Brasileira. (Originalmente publicado em 1898).

Nery, M. P., \& Costa, L. F. (2008). A pesquisa em psicologia clínica: do indivíduo ao grupo. Estudos de Psicologia (Campinas), 25 (2), 241-250. doi: 10.1590./s0103-166X2008 000200009

Pain, J. S., \& Almeida Filho, N. (2000). A crise da saúde pública e a utopia da saúde coletiva. Salvador: Casa da Qualidade.

Santos, N. R. (2009). Reforma sanitária e o sistema único de saúde: tendências e desafios após 20 anos. Saúde em Debate, 23 (81), 13-26.

Santos, C. E., \& Costa-Rosa, A. (2007). A Experiência da toxicomania e da reincidência a partir da fala dos toxicômanos. Estudos de Psicologia (Campinas), 24 (4), 487-502. doi: 10.159/S0103-166X2007000400008.

Tenório, F. (2000). Desmedicalizar e subjetivar: a especificidade da clínica da recepção. Cadernos IPUB, 17 (1), 79-91.

Tenório, F. A. (2001). Psicanálise e a clínica da reforma psiquiátrica. Rio de Janeiro: Rios Ambiciosos.

Recebido em: 6/11/2008

Versão final reapresentada em: 5/8/2010

Aprovado em: 25/8/2011 